\title{
Interpolation of Intensity Contour Map using Kriging Method
}

\author{
HU Yang ${ }^{1,}$, TAO Dongwang ${ }^{1}$
}

\author{
${ }^{1}$ Key Laboratory of Earthquake Engineering and Engineering Vibration, Institute of Engineering \\ Mechanics, China Earthquake Administration, Harbin 150080, China \\ a951865088@qq.com
}

\begin{abstract}
Keywords:.Intensity Contour Map; Intensity Rapid Reporting; Kriging Interpolation; Attenuation Relationship; Experimental Semivariogram

Abstract. The intensity contour map can directly reflect the damage degree of an earthquake, and it is an image representation of a seismic influence field or ground motion intensity field. The Kriging interpolation method is an unbiased and optimal interpolation method, and this method can be used to rapidly process data of the sampling points and to build smooth intensity fields after earthquakes, as one of outputs of intensity rapid reporting, and consequently, the intensity contour map can serve earthquake emergency response. The article briefly describes the basic principle of Kriging interpolation method and puts forward the problems existing in experimental semivariograms in practice, and to solve the problem, the ground motion intensity attenuation relationship is used to re-match experimental semivariograms. The instrumental intensity data is assumed as regional variation, and it conducts Kriging interpolation computation of artificial models and actual earthquake cases, finally the calculation results are analyzed and discussed.
\end{abstract}

\section{Introduction}

The seismic intensity rapid report is to use the strong-motion earthquake observation records to rapidly calculate the degree of seismic influence of all observation points, without need of field investigation, and to provide a complete seismic influence field and rapid release, providing a basis for the estimation of casualties and economic losses and the decision-making of earthquake emergency response and engineering emergency repairing. The contour map combines graphs and figures and it is direct and visual, so it is one of essential graphs in the rapid reporting of intensity of ground motion [1]. In this article, the rapid generation of intensity contour maps is realized according to the actual situation of strong motion observation network of our country and with the Kriging interpolation method. Within the influence scope of earthquake, high-quality instrumental data can rival macroeconomic intensity data of earthquakes of which the moment magnitude and attenuation relationship are given [2-3]. In other words, it is feasible to build an intensity field with instrumental intensity, but is shall be combined with the characteristics of ground motion. This article introduces the ground motion intensity attenuation relationship into the Kriging interpolation method, and it matches the spatial structure relationship of regional variation via the attenuation relationship so as to obtain a new experimental semivariogram, and then it re-allocates the weight of sampling pints in the interpolation method and finally obtains the intensity value of non-sampling points. At the end, the article verifies the method, analyzes the factors affecting the accuracy of the method.

\section{Method}

The Kriging interpolation method was first raised by D.G. Krige, a gold mine engineer in South Africa, in 1950s [4]; In 1960s, it was raised to theory by Matheron, a French mathematician [5]. It is a method developed in order to solve the calculation of reserves of ore deposits and error estimation, and it is an important constituent part of geostatistics. The estimated value of attribute value of $\mathrm{Z}\left(\mathrm{x}_{0}\right)$ at the point $x_{0}$ to be estimated is the weighted average of attribute values of sampling points [6]:

$$
\mathrm{Z}\left(\mathrm{x}_{0}\right)=\sum_{\mathrm{i}=1}^{\mathrm{n}} \lambda_{\mathrm{i}} \mathrm{Z}\left(\mathrm{x}_{\mathrm{i}}\right)
$$


where, $\lambda_{\mathrm{i}}$ is the weight coefficient to be determined using the follow Lagrange equations

$$
\begin{gathered}
\lambda_{1} \gamma\left(\mathrm{x}_{1}, \mathrm{x}_{1}\right)+\mathrm{L}+\lambda_{\mathrm{n}} \gamma\left(\mathrm{x}_{1}, \mathrm{x}_{\mathrm{n}}\right)+\mu=\gamma\left(\mathrm{x}_{0}, \mathrm{x}_{1}\right) \\
\lambda_{1} \gamma\left(\mathrm{x}_{2}, \mathrm{x}_{1}\right)+\mathrm{L}+\lambda_{\mathrm{n}} \gamma\left(\mathrm{x}_{2}, \mathrm{x}_{\mathrm{n}}\right)+\mu=\gamma\left(\mathrm{x}_{0}, \mathrm{x}_{2}\right) \\
\mathrm{M}+\mathrm{O}+\mathrm{M}+\mu=\mathrm{M} \\
\lambda_{1} \gamma\left(\mathrm{x}_{\mathrm{n}}, \mathrm{x}_{1}\right)+\mathrm{L}+\lambda_{\mathrm{n}} \gamma\left(\mathrm{x}_{\mathrm{n}}, \mathrm{x}_{\mathrm{n}}\right)+\mu=\gamma\left(\mathrm{x}_{0}, \mathrm{x}_{\mathrm{n}}\right) \\
\lambda_{1}+\mathrm{L}+\lambda_{\mathrm{n}}+0=1
\end{gathered}
$$

where, $\gamma\left(\mathrm{x}_{i}, \mathrm{x}_{j}\right)=\gamma\left(\mathrm{x}_{j}, \mathrm{x}_{i}\right)$ is experimental semivariogram[7-8]; $\mu$ is Lagrange multiplier.

The attenuation relationship is an empirical relationship depending on regions [9]. This article adopts the intensity attenuation relationship of the fifth generation of intensity division map of our country. The attenuation relationship is the seismic intensity attenuation relationship of all zones regressed on the basis of determining the zoning of our country's ground motion attenuation relationship, and its model is as follows:

$$
I=\mathrm{A}+\mathrm{B} M+\mathrm{C} \log \left(R+R_{0}\right)
$$

where, $I$ is the seismic intensity; $M$ is the surface wave magnitude; $R$ is the epicentral distance; A, B, C and $R_{0}$ are regression coefficients. The theoretical variation model adopted in the article is the power function model: $\gamma(h)=k h^{\alpha}$.

\section{Result}

The method mentioned above is applied in an artificial model of intensity field, as shown in Figure 1. In the model, $(0,0)$ point is taken as the epicenter, surface wave magnitude of earthquake is 6.5 ; the intensity attenuates from the epicenter to the surrounding by the attenuation relationship of ellipse. The selected attenuation relationship is the attenuation relationship of Qinghai-Tibet zone in the fifth generation of zoning map of our country, and the east-west direction is the direction of long axis. Sampling points are randomly selected in the intensity field according to the intensity (corresponding to stations in Figure 1), and the intensity of points are calculated. The number of sampling points are shown in Table 1.

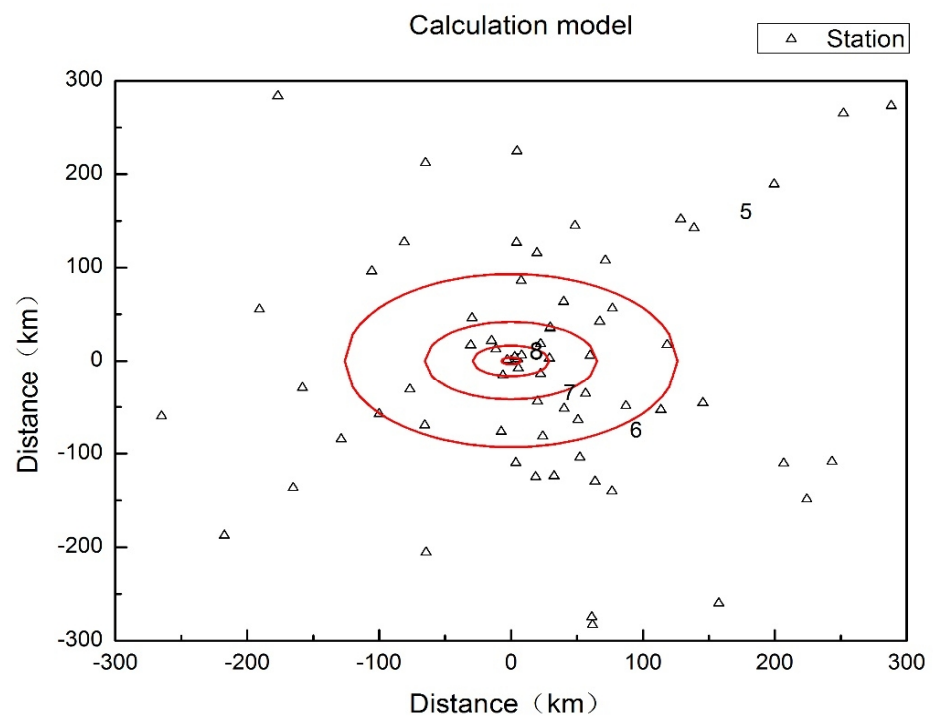

Figure 1. Schematic Diagram of Calculation Model 
Table 1. Distribution and Statistics of Sampling Points (Stations)

\begin{tabular}{cccccccc}
\hline $\begin{array}{c}\text { Scope of } \\
\text { intensity }\end{array}$ & 8 and more & $7 \sim 8$ & $6 \sim 7$ & $5 \sim 6$ & $4 \sim 5$ & $3 \sim 4$ & Total \\
\hline $\begin{array}{c}\text { Number of } \\
\text { stations }\end{array}$ & 3 & 5 & 8 & 15 & 20 & 20 & 71 \\
\hline
\end{tabular}

On the basis of calculation of error-free intensity, the added random error is increased, and then the interpolation calculation is conducted with the ordinary Kriging method, and the calculation result is shown in Figure 2. The numerical values of contour lines are $5 \sim 8$ from the outside to the inside. In the figure, the calculated data of $a$ is error-free data; the fluctuation error of calculated data of $b$ is $-0.1 \sim 0.1$; the fluctuation error of calculated data of $\mathrm{c}$ is $-0.2 \sim 0.2$; the fluctuation error of calculated data of $d$ is $-0.5 \sim 0.5$. It can be seen that the intensity field re-built based on error-free data by use of ordinary Kriging interpolation can nearly perfectly coincide with the original intensity field; however, with the increase of data errors of intensity, the intensity field built will be worse.

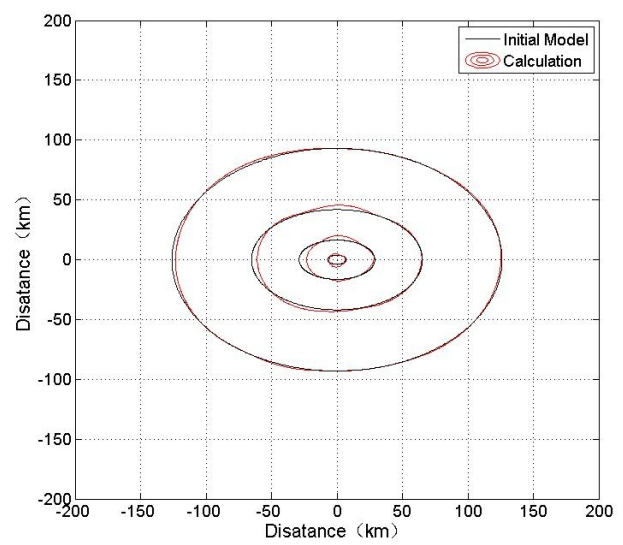

a. Data without error

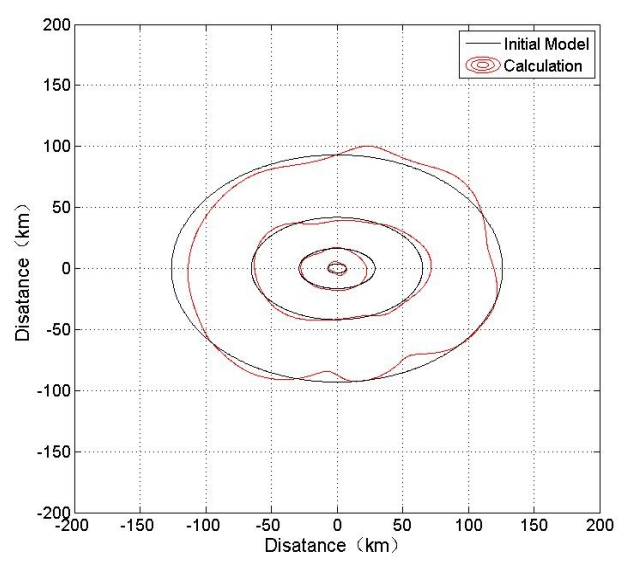

c. The error range is \pm 0.2

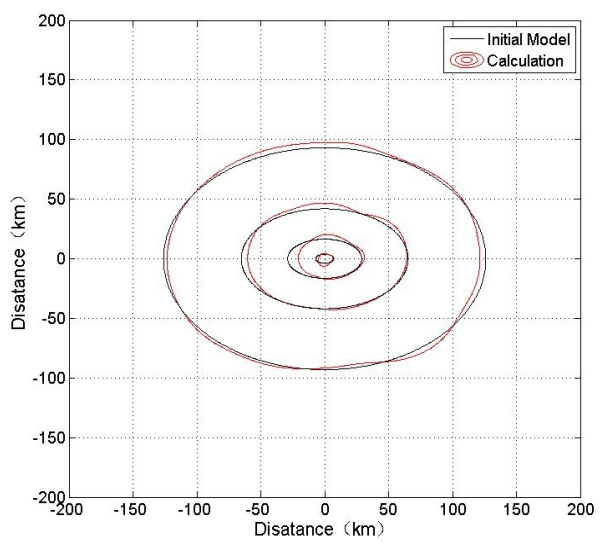

b. The error range is \pm 0.1

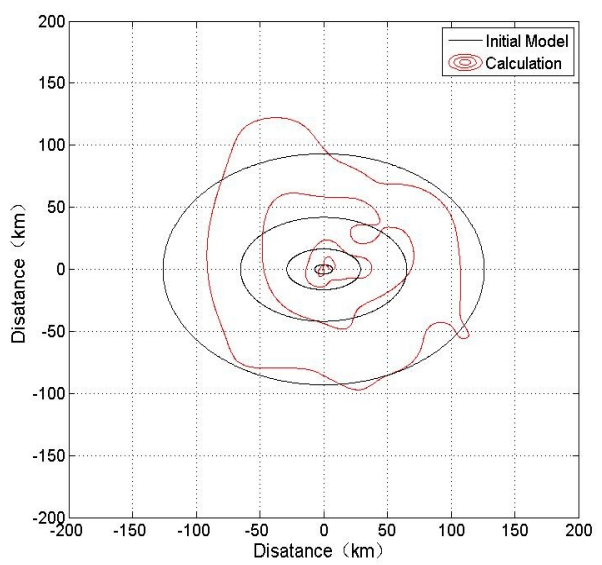

d. The error range is \pm 0.5

Figure 2. Calculation Results of Data of Different Error Ranges

\section{Conclusion}

Through the calculation examples, it can be seen that the Kriging interpolation method can be used to directly build a ground motion intensity field directly via the instrumental intensity of sampling points, and the experimental semivariogram fitted by the ground motion attenuation relationship can well represent the spatial autocorrelation of the variables. The rebuilt intensity field shows that the error of the sampling density and the sampling data will produce influences on the accuracy degree of intensity 
field, and in comparison, the error of sampling data will have larger influences on the rebuilt intensity field.

\section{Acknowledgements}

This work was supported by Scientific Research Fund of Institute of Engineering Mechanics, China Earthquake Administration (2016QJGJ21, 2016A03), National Natural Science Foundation of China (5150082083).

\section{References}

[1]. Li Shan-you, Jin Xing, Chen Xian, Ma Qiang. Rapid reporting of peak strong motion and seismic intensity[J]. Earthquake Engineering and Engineering Vibration, 22(6):1-7, 2002 (in Chinese).

[2]. Schenkova Z., Schenk V, Kalogeras I, et al. Isoseismal maps drawing by the kriging method[J]. Journal of Seismology, 2007.

[3]. Frankel A. Implication of felt area-magnitude relations for earthquake scaling and the average frequency of perceptible ground motion[J]. Bulletin of the Seismological Society of America, 84(2):462-465, 1994.

[4]. Krige, D.G. A statistical approach to some mine valuations and allied problems at the Witwatersrand. Master's thesis of the University of Witwatersrand, 1951.

[5]. Matheron, G., Principles of geostatistics, Economic Geology, 58:1246-1266, 1963.

[6]. Yang Gong-liu, Zhang Gui-min, Li Shi-xin. Application of universal Kriging interpolation in geomag-netic map[J]. Journal of Chinese Inertial Technology, 16(2):162-166, 2008 (in Chinese).

[7]. Li Zhang-lin, Wang Ping, Li Dong-mei. Research and application of the method calculating experiment variogram[J]. Land and Resources Information, 8(2):10-14, 2008 (in Chinese).

[8]. Valerio De Rubeis, Patrizia Tosi, Calvino Gasparini, and Alessandro Solipaca. Application of Kriging technique to seismic intensity data[J]. Bulletin of the Seismological Society of America, 95(2):540-548, 2005.

[9]. Yu Yan-xiang, Li Shan-you, and Xiao Liang. Development of ground motion attenuation relations for the new seismic hazard map of China[J]. Technology for Earthquake Disaster Prevention, 8(1):24-33, 2013 (in Chinese). 